\title{
Measuring by Interpretive Structural Model the Perceived Barriers for GSCM Practices in Indian SME's
}

\author{
Mustafa Md. Sajid, Shiva Prasad H C, Yogesh Pai, Alapati Vittaleswar
}

\begin{abstract}
Environmental protection is the primary responsibility of any contemporary Indian manufacturing organization. The trade barriers and meeting the regularities for the supplier in the developing countries to supply their products globally has to face multiple challenges in both importing and exporting. However, the concept of green practices is relatively new to the Indian manufacturing industry, specifically to small and medium scale industries (SME). The SME finds it challenging to practice green concepts due to a lack of green-related education and practitioners. An extensive literature review carried out to identify the practical barriers to Green Supply Chain Management (GSCM) practices. They identified nine barriers are studied thoroughly and analyzed using Interpretative Structural Modelling (ISM) technique. The identified barriers are classified using Matrice d'Impacts croises-multiplication appliqúe an classment (MICMAC) analysis to determine the driving and dependence power of each barrier. The benefaction from this study is to find out the dominant barriers to GSCM practice in the Indian industry and helps to understand the high priority barriers with strong driving and craving power. The developed model using the ISM technique helps the Indian manufacturing industry to understand interdependencies and contextual relationships of the obstacles.
\end{abstract}

Index Terms: Barriers, Drivers, Green Supply Chain Management, Interpretative Structural Modelling.

\section{INTRODUCTION}

The awareness of environmental protection is inflating day by day. The conservation and security of the earth's resources and the environment are swamping that is exerting pressure on corporations. The essential issues exclusive of the change in global manufacturing scenarios are biodegradable and social. So, the companies, along with the government from different countries, recognized the need for coming to a common motive of protecting the environment by taking corrective action. Drawing parallels on the clean supply chain management,well-established frameworks are in place [1]. The twenty-first-century calls for a smarter production system with a clean-green-lean supply to manufacturing. Due to this reason, the Green Supply Chain Management (GSCM) has become one of the solutions to preserving the

Revised Manuscript Received on November 25, 2019.

* Correspondence Author

Mustafa Md. Sajid PG Scholar, Department of Humanities and Management, MIT, Manipal Academy of Higher Education (MAHE) Manipal, India.

Shiva Prasad H CProfessor, Department of Mechanical Engineering School of Automobile, Mechanical, and Mechatronics, Faculty of Engineering, Manipal University Jaipur, Jaipur, Rajasthan, India.

Yogesh Pai Assistant Professor, School of Management, Manipal Academy of Higher Education (MAHE) Manipal, India.

Dr. Alapati Vittaleswar Professor, Department of Humanities and Management, MIT, Manipal Academy of Higher Education (MAHE) Manipal, India (Corresponding Author). environment.

In recent years, the changing climate and environment are due to waste and disrupted ecosystems, and the firms, along with the supply chain partners, do recognize the importance of GSCM. However, firms are still hesitating to bring out green practices into their supply chain because of cost-related barriers. The drift of GSCM is to ensure whether organizations are sticking with four R's principles, i.e., recycling, remanufacturing, reclamation, and reverse logistics.

Different researchers have examined the relationship between GSCM and the firm's performance and hence identified that firms with green practices demonstrate better environmental performance by practicing green and clean technologies. As there are rapid industrialization and modernization, there is a cascading impact on the environment resulting in increased greenhouse emission gas, toxic pollution, and chemical spills. In response to the environmental issues, GSCM is a compelling concept that combines the natural thinking intra-and-inter-manufacturing firm management of the upstream and down streaming supply chain processes. The growing concern for the environment is green branding and sustainability, which is much more important for sustaining in the market. Moreover, there is a rapid change in the environment; environmental policies for the manufacturing process have changed the strategies for the supply chain process. Recognizing the barriers of GSCM practices in the Indian context and prioritizing the obstacles with an extended structural model of interdependencies in the process of SCM brings a new dimension analysis to the government and global policymakers to protect the environment[2].

Research findings show that an integrated strategic approach to the supply chain helps in synchronization of theproduction process with the organizational goal. There is a requirement for better coordination between different processesand departments because the business environment has changed drastically and has become more competitive. Hence companies need an integrated strategic approach for successful coordination of technology logistics, material distributions, and transportation functions that are critical ingredients for the supply chain management. The concept of GSCM finds its roots in the integration of environmental thinking into supply chain management. In the supply chain process, wastage occurs,starting from designing a product until finishing further it reaches the consumer.

In the entire chain, hazardous chemicals, emissions of energy, and solid waste materials get transmitted at all levels. The goal of GSCM is to minimize these wastages/ eliminate. The GSCM 
improves profit and market share by reducing waste and saving costs as well as improves the ecological efficiency of the organization.

The sustainable model of supply chain management leads to the economic growth of the company that is concern about the environment viewed from the kaleidoscope of GSCM. Indian industries are trying to become environmentally sustainable, and GSCM is trending as a critical approach for enterprises that helps to achieve the effect of the entire supply chain on the ecosystem and economic development. However, it is a challenge to achieve a balance between ecosystem and economic development. Thus, GSCM implementation and practicing become essential for industries while the globally competitive business environment is increasing, and regularities have to frame strict governmental regulations and reduce the social cost. The GSCM practice has a limitation while little awareness of the GSCM concept among the Indian industries and their concern for the environment is shallow while comparing it with developed countries in comparing the SME sector. However, it is pragmatic that implementation of GSCM practices from the existing supply-chain management (SCM) to GSCM plays a critical component of maintaining games plan to take a competitive advantage that is perceived barriers for the implementation of the new paradigm shift to SME industries in India [3].

This study attempts to design a structural model that helps to identify the critical barriers and their interdependencies as well as the relationship to the supply chain process. In order to achieve these the following objectives are formulated: (a) to identify the dominant barriers and find the contextual relationship among them (b) to develop an ISM of barriers to GSCM, (c) to categorize the different barriers affirming to their driving and dependence power using fuzzy Matrice d'Impacts croises-multiplication appliqúe an classment (MIC MAC) analysis.

\section{LITERATURE REVIEW}

In earlier days, managers were involved only to ensure whether organizations are meeting environmental regulations set by the government,and the rest of the work was under the supervision of a separate organizational unit. However, days are changed now, and after the quality revolution in the eighty decades and supply chain revolution in the 1990s, managers are trying to integrate best practices of environmental management with ongoing operations. However, it is not about to meet the environmental regulations and minimize the waste and emission of greenhouse gas; it is about cost reduction and higher profit. [4]found that due to environmental laws and consumer pressures, the scope of GSCM (GSCM) has increased in proactive practices through different R's such as reduce, reuse, rework, reclaim, recycle, reverse logistics. Reference [5]claims that supply chain management (SCM) plays a significant role in an organization to increase performance as well as the profit of the organization and helps in reducing inventory. It is found to have global warming and becomea trend of adopting models of environmental sustainability [6]. Some researchersclaim that ecological issues are getting more critical from the past few decades, and a sustainable supply chain has gained the attention of practitioners to stand against environmental issues[7]. Industries are attempting to add the green term in their traditional supply chain to reduce waste such waste material during production, utilization of energy, and resources in a correct way and meet customer requirements. Due to the increase in environmental concern, customers are now more focused on green-related products and processes. [4] found that many researchers and practitioners found that the fundamentals of green practices are resource-saving, waste elimination, and improving productivity.

Reference [8]found that small and medium-sized companies play significantly in economic growth for a country, and their impact on the environment is low as the individual, but together they make a significant impact on the environment. Due to this reason, GSCM had a substantial effect on small and medium-sized companies to increase efficiency, reduction of cost, and sustainability of resources. Due to environmental pressure by local government and global players, small and medium-sized companies are facing pressure to adopt GSCM. It is claimed that supply chain management is a traditional way to improve the efficiency and performance of an organization, whereas GSCM is an accession of improving performance considering environmental issues [9]. The integration of green terms in the traditional supply chain has become essential for an organization due to the change of climate as well as market competition. It is studiedthat the environment is affected as such the carbon dioxide emission, waste material during product manufacturing, solid waste, wastewater, and radiation, which are directly impacting the ecosystem due to the business activities [10]. Reference [11]advocate that global manufacturing scenario changes day-by-day rapidly along with environmental issues, government, policymakers, and global players are introducing new regulations frequently, and the industries are trying to meet those regulations to maintain their competitive advantages. Hence, it is becoming challenging for small and medium-sized companies to meet environmental rules with traditional supply chain and so they are pushed to adopt GSCM to maintain their position in the global market.

Reference [12],in their research, narrates that India is one of the developing countries, and it has enormous economic growth, and small and medium-sized firms have a significant contribution to this growth.

From the past decade, the number of small and medium-sized firms has increased along with environmental issues, and hence local government and policymakers introduced strict regulations regarding ecological management. Consequently, demand for GSCM has increased to small and medium-sized companies in India. The companies are recognizing that environmental protection is growing,and maintaining performance is becoming hard concerning ecological standards [13].

Hence green practices become the essential concern for businesses to incorporate environmental issues into the forward and reverse logistics as it reduces packaging and waste and develops the eco-friendlier product. Increasing social pressures, pressures from global players 
and local government, green consumerism, green packaging have led to the assiduity towards the encounter of supply chain movements on the natural environment as well as the generation of environmental performance change. While [5] investigates the small and medium-sized companies play a significant cardinal role in forming the profit-making foundation for the different states of India. Hence most Indian companies need to shift or modify their existing SCM to GSCM to environmental sustainability, starting with the green procurement strategies.

The authors like [14] have found that the aftermath of climate change and global warming are increasing in the mind of consumers, andhence, this matter is taken seriously not only by industries and practitioners but also consumers. Enterprises are facing problems in reducing waste, $\mathrm{CO} 2$ emission, and utilization of energy. The ISO 50001 supports GSCM (GSCM), and it gives the knowledge of how to rock pile green and low carbon supply chain. The ISO 50001 is for an energy management system that continuously supports in improving energy efficiency. The implication of ISO 50001 results in improving energy efficiency, reduction of co2 emission, and other environmental issues. In a study by [15],they have found that in previous years, the attention towards environmental sustainability has increased due to many increases of carbon emission that raised essential questions on the efforts required to make businesses more sustainable environmentally. As lifestyle changes, the needs of daily life also change,increasing demand for products that led to supply chain issues such as higher levels of logistics and transportation that further led to higher carbon emission. Reference [16]claim that due to an increase in pollution and population, the conservation of environmental resources and meeting the environmental requirements has become essential. The practice of GSCM has become mandatory to balance environmental problems. According to the World Commission on Environment and Development (WCED), current environmental patterns and issues have altered the planet along with its living organisms, including human beings. Hence green practices have come to view as an essential research topic in recent years. The original dimensions of GSCM are green procurement, green manufacturing, green distribution, and green logistics for firms to bring out enhanced sustainability performance.

The supply chain activities have increased due to an increase in industrial growth worldwide, and these activities are the principal determinants in the reduction of natural reservoirs, climatic problems, waste generation, baleful emission of gases, and severance in the ecosystem. So, GSCM combines the principles of natural management with supply-chain activities to counter environmental issues to improve and preserve it. It is believed that various actions of supply chain management (SCM) trigger at the starting pointthe raw material collected from the sources to the final product reaches in the hands of the customer, and so it has become one of the promising research areas [16]. The observed that GSCM plays a prime role in the building of sound economic-environmental performances on various levels in business, and the successful pursuit of GSCM in many industries in different countries is evidence of that. On the contrary, in developing nations like China, India, Taiwan, enterprises are still facing problem to enforce GSCM. There are several reasons behind this, but the most important is the lack of green knowledge and financial constraints. However, companies must be aware of the long-term benefit of practicing GSCM. Explaining through ISM approach and put forward in Indian industries and the solicitous managers in the industry realized that green business practices are not easy to bring out in an organization due to so many hurdles and so to make that easy, a qualitativesurvey is conveyed to recognize those hurdles or barriers [10],[18]. Various barriers recognized from the literature reviews and expert suggestions to enforce the GSCM concept in the Indian industry and the different obstacles identified (see Table 1).

\section{A. Barrier Variables Identification}

\section{A. Top management support}

Top management plays a vital role in the exertion and enforcing of innovations in an organization, especially environmental systems. Senior management increases the commitment of the organization's employees by facilitating employee engagement, and this affects the new initiative. Adverse management impacts on employees as well as the organizational culture that result in low employee morale. Due to lack of motivation, employees complain to each other and put minimal efforts into their job and fail to finish their assignments that,in turn, affect organizations to achieve their goals.

Table I. Literature evidence for barriers to GSCM concept

\begin{tabular}{|l|l|l|}
\hline Code & Barriers & References \\
\hline B1 & $\begin{array}{l}\text { Top Management } \\
\text { support }\end{array}$ & $\begin{array}{l}{[5],[6],[7],[8],[9] \quad[10],} \\
{[11],[12],[18],[19],} \\
{[20],[21],[22]}\end{array}$ \\
\hline B2 & Government support & $\begin{array}{l}{[4],[5],[6],[8][9],[11],} \\
{[12],[16],[19],[23],} \\
{[25]}\end{array}$ \\
\hline B3 & Financial constraints & $\begin{array}{l}{[4],[5],[6],[7],[8],[9],} \\
{[11],[12],[16],[19],} \\
{[23],[27]}\end{array}$ \\
\hline B4 & $\begin{array}{l}\text { Organisational } \\
\text { culture }\end{array}$ & $\begin{array}{l}{[4],[5],[6][9][10][11]} \\
{[12],[19],[27]}\end{array}$ \\
\hline B5 & $\begin{array}{l}\text { Environmental } \\
\text { ethical standards }\end{array}$ & {$[6],[22]$} \\
\hline B6 & Benchmarking & {$[22]$} \\
\hline B7 & $\begin{array}{l}\text { Performance } \\
\text { measurement system }\end{array}$ & {$[5],[22]$} \\
\hline B8 & Green design and & {$[4],[6],[8],[12],[16]$,} \\
& education & CO22] emission norms \\
\hline B9 & C14] \\
\hline
\end{tabular}

B. Government support

The government plays a significant role in the adoption of innovation as the government sets all the regulations. However, sometimes they introduce time-consuming rules that become exceedingly difficult for industries to adopt the green practice as day by day climates are changing, and the rate of pollution is increasing. Since all the environmental regulations are made based on climate change and environmental pollution, hence industries have a fear of changing rules soon, and therefore they hesitate to implement time-consuming processes. Thus, small and medium-sized companies find it arduous to adopt new technologies due to

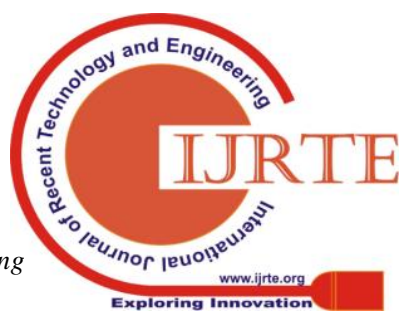


financial constraints and also lack of government support.

\section{Financial constraint}

For the successful implementation of the new system or existing upgrading system, the most basic requirement is financial resources. Without solid financial fundamentals, industries implementing successful GSCM is a challenging task as the cost is the prime performance measure. Since the initial investment of GSCM implementation is too high, the investors are also going to think about the return of investment, and hence, small and medium-sized companies have a fear of failure. Due to higher cost, downstream firms feel a lack of confidence towards implementing a GSCM strategy, whereas retailers doubt that their product may become too costly, and consumers need no longer be engrossment in purchasing. To perform a flexible GSCM company require the latest green technologies that are necessary, enough financial investment that is a long way off the range of small and medium-sized companies.

\section{Organizational culture}

It is a system that consists of shared postulation, values, and beliefs that shows how people react in an organization. These shared values show how people dress, act, and perform their jobs. Every organization has a unique culture that provides the guideline to employees, and it has a substantial impact on the performance of the organization. Organizational culture shows the framework of the organization that consists of the behaviour of employees, employee engagement, workforce culture. It has a positive as well as a negative impact on the organization. Depending on the positive nature of the organization culture, it improves employee engagement in the adoption of green practices.

\section{E. Environmental, ethical standards}

Simple words used are ethics as the moral standards to rely upon while deciding upon an issue. Environmental ethics is the study of human interaction with the environment. Environmental ethics is a part of environmental philosophy that studies the mystique connection between human beings and nature and its nonhuman contents. In business, ecological ethics is concerned about the company's response, i.e., how an organization reacts to protect the environment. Firms always change their ethics to maintain global environmental standards.

\section{F. Benchmarking}

Benchmarking is the process of comparing two organizations, their operations,orthe process of examining the competitive company with other organizations in broader marketplaces. Benchmarking is primarily done to improve a company's strategies concerning competitors. Due to the globalization of the past few decades, it has created global customers who expect the same kind of service levels from all companies. Benchmarking is not easy for every company as it is expensive. There are several types of costs involved in benchmarking. These are visited cost, time cost, and benchmarking database cost. While doing benchmarking, employees need to visit various companies, and hence, there is a need for additional employees, and some companies institutionalized benchmarking and for all these organizations need financial support. However, for small and medium-sized companies, project processes and financial resources are not enough, and hence, it is not possible to support benchmarking, and accordingly, it acts as the barrier to GSCM.

\section{G. Performance measurement system}

Performance refers to the outcome of the process that is done through evaluation, whereas measurement refers to numerical information that quantifies input, output with the help of units. A fair performance measurement system in place, an organizational assessment on what is happening and where it is happening,and why it is easy measure. So, the effective performance measurement system that acts as a guide to an organizational goal to produce meaningful results to achieve the organization's goals. Managers use a performance measurement system to manage each action to yield information regarding their functional portfolio of resources and capabilities. Many organizations use a performance measurement system to control their organizational behaviour.

Besides, this promotes innovation and strategic reassemble.Hence it highlights that in the adoption of innovations performance measurement system plays a crucial role as it reveals the performance metrics of an organization.

\section{$H$. Green design and education}

The meaning of green design is to make building or product that is harmless to humans, as well as the environment and green education, is the process that allows individuals to gather knowledge about environmental issues and engage in solving the problems. So, both of them are associated with green practices and the accumulation of green-related knowledge. For conducting training of employees to give green-related experience, some companies contract specialists, some train managers to session internally. However, the green practices in India are at the initial phase, and hence, there are limited edition of practitioners to have sufficient knowledge regarding green practices. Hence small and medium-sized enterprises are facing problems regarding the training of green practices of their employees.

\section{The CO2 emission norms}

The main reason for environmental pollution is $\mathrm{CO} 2$ emission, and from the past few decades, it is increasing rapidly. The biggest problem of this era to the global companies and governments are facing is the $\mathrm{Co} 2$ emission.

The main two goals due to which companies are putting efforts in the reduction of carbon emission are a voluntary commitment as a response to pressures from customers' preference and environmental groups and emission regulations set by the government and global policymakers. India is one of the fastest developing countries, and its economy is a growing major economy of the world. Since there are rapid climate change,and supply chain mainly depends on the energy that originates from $\mathrm{CO} 2$ emissions.

The GSCM is the way that acts as a counter to the thrusts of climate change. In India, cities are full of the high density of population, housing stock, and poor infrastructures, and due to this reason, cities are more vulnerable to climate change. $\mathrm{CO} 2$ emission norms are developing day by day, and hence small and medium-sized companies are pushed to adopt green practices, but due to the shift in environmental $\mathrm{CO} 2$ emission regulation, it is challenging for them to adopt and implement the green practice. It is not 24 possible to

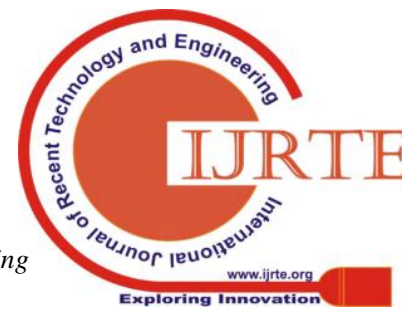


invest Hugh now and then, and hence, $\mathrm{CO} 2$ emission norms are becoming obstacles for industries to practice GSCM.

\section{METHODOLOGY}

The different types of barriers to the adoption of GSCM concept are found in the literature review and consulting with academics as well as industry experts. Hence the thought of ISM is operated for modeling and analyzing the identified barriers and their interdependencies.

\section{B. Interpretative Structural Modelling (ISM)}

ISM is an erudition process that helps to identify different directly and indirectly related components and Structure them into a systematic synoptic model. ISM is a well-established methodology that does a service to portray complex issues or problems in a system in a carefully designed model. For any issue or problem, there are multiple factors that are related,and the relationships between the direct and indirect factors describe the problem or issue far more accurately. This methodology starts with the identification of different factors of a problem or an issue which act as barriers. The identification of barriers is jolted down from the experts from academic as well as industry.

The various steps involved in developing an ISM model are:

Step 1:Different factors that act as barriers for the implementation of GSCM detected.

Step 2: The recognized barriers are investigated to find out the contextual connections between them.

Step 3: A structural self-interaction matrix (SSIM) amplified among the factors after the investigation of contextual connections among the factors in step2.

Step 4: The initial reachability matrix is developed from the SSIM matrix, and it is examined for transitivity to find out the final reachability matrix. To give an example, there exist a relation between $\mathrm{A}$ and $\mathrm{B}$ and the relation between $\mathrm{B}$ and $\mathrm{C}$ then it asserts that there is a relation between $\mathrm{A}$ and $\mathrm{C}$.

Step 5: The final reachability matrix accomplished in Step 4 is segregated into different levels by the iteration process.

Step 6: A diagraph is drafted after removing the transitivity connections from the final reachability matrix. 26

Step 7: The final diagraph is switched into an Interpretive Structural Model by altering variable nodes with barriers name.

\section{A. Structural Self-Interaction Matrix (SSIM)}

ISM methodology based on an expert's suggestion. To find out the exact relationship between variables, a group of experts uses different management methods brainstorming, nominal group technique, Delphi method. For this process, experts from academic as well as industry discussion on the interdependencies nature of various variables and their relationships. Experts should consider all the facts regarding variables and their relationships. For analyzing, a contextual connection of 'lead to' or 'influences' type must be used. With the assist of four attributes, the direction of the connection between variables $(\mathrm{a}, \mathrm{b})$ is designated as follows: V: Factor a guide's factor $b$

A: Factor $b$ guides factor $a$

$\mathrm{X}$ : Factor $\mathrm{a}$ and $\mathrm{b}$ guide each other

$\mathrm{O}$ : Factor $\mathrm{a}$ and $\mathrm{b}$ are irrelevant.

Depending on the contextual connection, the SSIM is amplified for nine variables recognized as GSCM barriers, and following would make clear the utilization of attributes $\mathrm{V}, \mathrm{A}, \mathrm{X}$, and $\mathrm{O}$ in SSIM (Table 2).
B1 guides B3 and this designates that barrier,namely 'top management support,' guides barrier 'financial constraints.' Thus, the connection between B1 and B3 is attributed to ' $\mathrm{V}$ ' in the SSIM.

B2 guides B1 and designates that barrier 'top management support' is guided by the barrier 'government support,' thus the connection between B1 and B2 is attributed by ' $A$ ' in the SSIM.

B3 and B7 guide each other so that designates that barrier,namely 'financial constraints' and 'performance measurement system', assist in guiding each other.

Thus, the connection between B3 and B7 is attributed to ' $\mathrm{X}$ ' in the SSIM.

$\mathrm{B} 2$ and $\mathrm{B} 4$ have no relation and implies that there is no connection exists between the barriers,namely government support and organizational culture. Thus, the connection between $\mathrm{B} 2$ and $\mathrm{B} 4$ is designated by ' $\mathrm{O}$ ' in the SSIM.

Table 2. Structural Self-Interaction Matrix

\begin{tabular}{|c|c|c|c|c|c|c|c|c|}
\hline & B9 & B8 & B7 & B6 & B5 & B4 & B3 & B2 \\
\hline B1 & V & V & V & V & V & V & X & A \\
\hline B2 & V & V & O & O & O & O & V & X \\
\hline B3 & A & V & X & V & V & O & X & \\
\hline B4 & A & X & X & O & X & X & & \\
\hline B5 & O & X & V & V & X & & & \\
\hline B6 & A & A & V & X & & & & \\
\hline B7 & O & O & X & & & & & \\
\hline B8 & X & X & & & & & & \\
\hline B9 & X & & & & & & & \\
\hline
\end{tabular}

\section{B. Initial Reachability Matrix}

The SSIM is converted into a binary matrix by substituting $\mathrm{V}, \mathrm{A}, \mathrm{X}$, and $\mathrm{O}$ by 1 and 0 as per the substitution rules, which is called an initial reachability matrix (Table 3 ). The following rules were followed for the substitution of 1 and 0 values:

a) If the value for $(a, b)$ in SSIM is V, then for reachability matrix $(a, b)$ is one and $(b, a)$ is 0 .

b) If the value for $(a, b)$ in SSIM is A, then for reachability matrix $(a, b)$ is 0 and $(b, a)$ is 1 .

c) If the value for $(a, b)$ in SSIM is X, then for reachability matrix $(a, b)$ is one and $(b, a)$ is 1 .

d) If the value for $(a, b)$ in SSIM is O, then for reachability matrix $(a, b)$ is 0 and $(b, a)$ is 0 .

\section{Table 3: Initial Reachability Matrix}

\begin{tabular}{|l|l|l|l|l|l|l|l|l|l|}
\hline & B1 & B2 & B3 & B4 & B5 & B6 & B7 & B8 & B9 \\
\hline B1 & 1 & 0 & 1 & 1 & 1 & 1 & 1 & 1 & 1 \\
\hline B2 & 1 & 1 & 1 & 0 & 0 & 0 & 0 & 1 & 1 \\
\hline B3 & 1 & 0 & 1 & 0 & 1 & 1 & 1 & 1 & 0 \\
\hline B4 & 0 & 0 & 0 & 1 & 1 & 0 & 1 & 1 & 0 \\
\hline B5 & 0 & 0 & 0 & 1 & 1 & 1 & 1 & 1 & 0 \\
\hline B6 & 0 & 0 & 0 & 0 & 0 & 1 & 1 & 0 & 0 \\
\hline B7 & 0 & 0 & 1 & 1 & 0 & 0 & 1 & 0 & 0 \\
\hline B8 & 0 & 0 & 0 & 1 & 1 & 1 & 0 & 1 & 1 \\
\hline B9 & 0 & 0 & 1 & 1 & 0 & 1 & 0 & 1 & 1 \\
\hline
\end{tabular}

\section{Final Reachability Matrix}

The final reachability matrix is obtained from the initial reachability matrix by following transitivity law,whichis mentioned in step four of ISM methodology. This matrix aids in finding the diving and dependence power of all barriers. Driving power of a particular barrier ascribes to the number of barriers guided by it,andthe dependence power of a 
particular barrier ascribes to the number of barriers influencing it.

Table 4: Final Reachability Matrix

\begin{tabular}{|l|l|l|l|l|l|l|l|l|l|}
\hline & B1 & B2 & B3 & B4 & B5 & B6 & B7 & B8 & B9 \\
\hline B1 & 1 & 0 & 1 & 1 & 1 & 1 & 1 & 1 & 1 \\
\hline B2 & 1 & 1 & 1 & $1^{*}$ & $1^{*}$ & $1^{*}$ & 0 & 1 & 1 \\
\hline B3 & 1 & $1^{*}$ & 1 & 0 & 1 & 1 & 1 & 1 & 0 \\
\hline B4 & 0 & 0 & 0 & 1 & 1 & 0 & 1 & 1 & 0 \\
\hline B5 & 0 & 0 & 0 & 1 & 1 & 1 & 1 & 1 & 0 \\
\hline B6 & 0 & 0 & 0 & 0 & 0 & 1 & 1 & 0 & 0 \\
\hline B7 & 0 & 0 & 1 & 1 & $1^{*}$ & $1^{*}$ & 1 & $1^{*}$ & 0 \\
\hline B8 & 0 & 0 & 0 & 1 & 1 & 1 & $1^{*}$ & 1 & 1 \\
\hline B9 & 0 & 0 & 1 & 1 & $1^{*}$ & 1 & $1^{*}$ & 1 & 1 \\
\hline
\end{tabular}

\section{Level Proportions}

The prime sets required for level partition are reachability set and antecedent set. Both setsare arbitrated from the final reachability matrix [24]. The reachability set exists with barriers and barriers that guide the antecedent set exists with a barrier. The intersection set detects the reachability and antecedent set. The level partition aids in composing the diagraph and modeling. The diagraphis based on the structural framework created. In case the connection between the GSCM barriers a and b exist, that is indicated with arrowheads with a to b. Diagraph is a term derived from the directional graph, which is a graphical representation of the constituents, their assisted relationships, and hierarchical levels. The initial diagraph is constructed using the canonical matrix. After extraction of the transitivity of the ISM methodology, the final diagraph is composed (refer to Figure 1) and is switched to the ISM-based model by altering variable nodes with the name of barriers (refer to Figure 2). The barriers having a coequal reachability set and the intersection set are allocated in level 1 (Table 5).

Table 5: Level Partition (Iteration 1)

\begin{tabular}{|c|c|c|c|c|}
\hline Codes & Reachability set & $\begin{array}{l}\text { Antecedents } \\
\text { set }\end{array}$ & Intersection & Level \\
\hline B1 & $1,3,4,5,6,7,8,9$ & $1,2,9$ & 1,9 & \\
\hline B2 & $1,2,3,4,5,6,7,8,9$ & 2,9 & 2,9 & \\
\hline B3 & $1,2,3,5,6,7,8$ & $1,2,3,4$ & $1,2,3$ & \\
\hline B4 & $4,5,7,8$ & $1,2,4,5$ & 4,5 & \\
\hline B5 & $4,5,6,7,8$ & $1,2,4,5,8,9$ & $4,5,8$ & \\
\hline B6 & 6,7 & $1,2,4,5,6,7,9$ & $4,5,6,7$ & 1 \\
\hline B7 & $3,4,5,6,7,8$ & $1,2,4,5,6,7,9$ & $4,5,6,7$ & 1 \\
\hline B8 & $4,5,6,7,8$ & $1,4,5,8,9$ & $4,5,8$ & \\
\hline B9 & $3,4,5,6,7,8,9$ & 9 & 9 & \\
\hline Aft & & 9 & & \\
\hline
\end{tabular}

After the level lis completed, barriers are evicted with iteration followed. Completing the iteration process, level barriers allocated (see Table 6).

Table 6: Level Partition

\begin{tabular}{|c|c|c|c|c|}
\hline Codes & $\begin{array}{c}\text { Reachability } \\
\text { set }\end{array}$ & $\begin{array}{c}\text { Antecedents } \\
\text { set }\end{array}$ & Intersection & Level \\
\hline B1 & 1,9 & $1,2,9$ & 1,9 & 5 \\
\hline B2 & 2,9 & 2,9 & 2,9 & 5 \\
\hline B3 & $1,2,3$ & $1,2,3,4$ & $1,2,3$ & 3 \\
\hline B4 & 4,5 & $1,2,4,5$ & 4,5 & 2 \\
\hline B5 & $4,5,8$ & $1,2,4,5,8,9$ & $4,5,8$ & 2 \\
\hline B6 & 6,7 & $1,2,4,5,6,7,9$ & 6,7 & 1 \\
\hline B7 & $4,5,6,7$ & $1,2,4,5,6,7,9$ & $4,5,6,7$ & 1 \\
\hline B8 & $4,5,8$ & $1,4,5,8,9$ & $4,5,8$ & 2 \\
\hline B9 & 9 & 9 & 9 & 4 \\
\hline
\end{tabular}

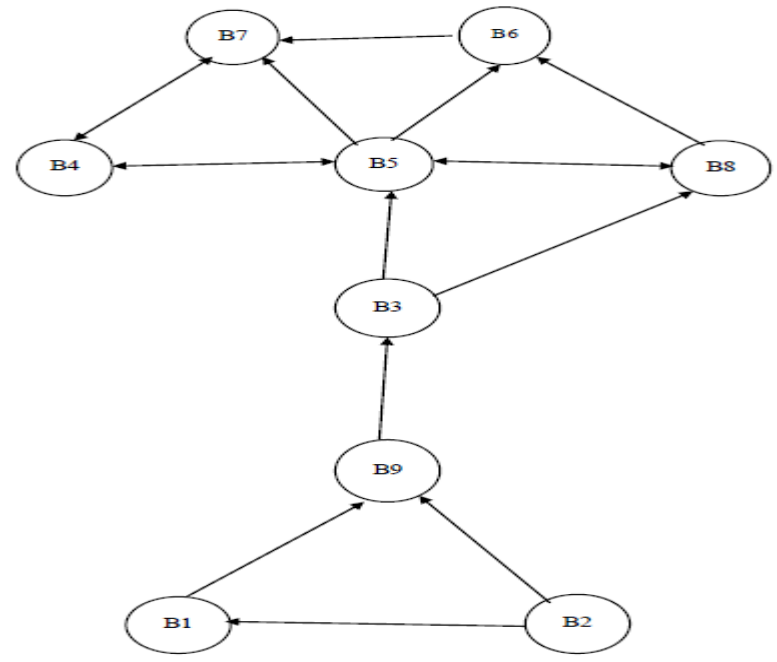

Fig1: Final Diagraph

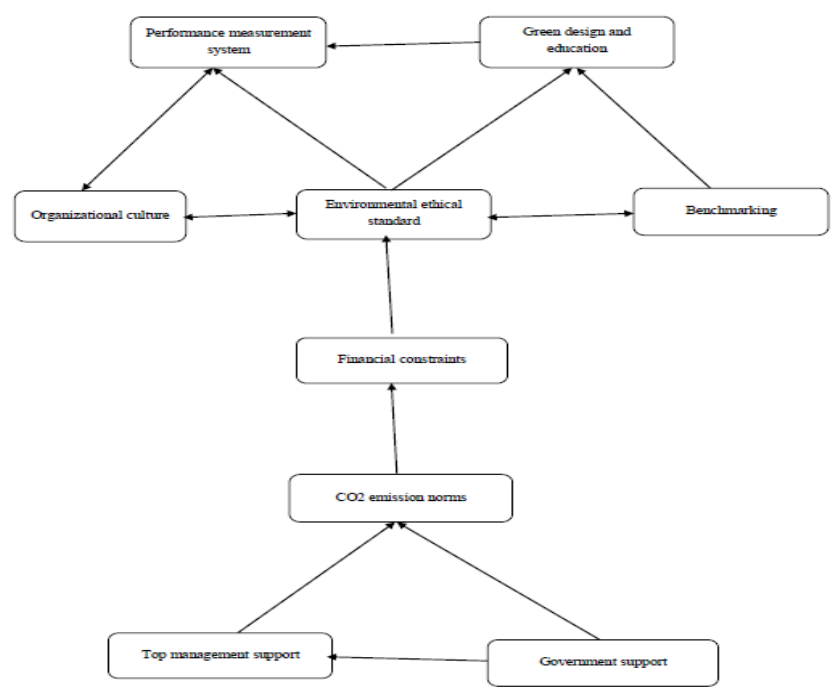

Fig 2: ISM Based GSCM framework model

\section{E. MICMAC Analysis}

The direct and indirect relationships of barriers in the reachability matrix are carried out by ISM and fuzzy MICMAC. The initial reachability matrix is the direct reachability matrix which is developed by the straight relationship among the barriers. All the connections in that matrix have equal weight designated by one.

However, there are some direct relationships which are very strong, and some are medium, and some are low. However, to mitigate these issues, fuzzy MICMAC analysis is used,which helps to find out the strength of the relationship between two barriers. It also helps to find out the driving and dependence power of all barriers, and the procedure followed by [25] is followed in the next section covers the steps of MICMAC.

\section{A. Binary Direct Relationship Matrix (BDRM)}

This matrix is obtained from the final reachability matrix by changing diagonal elements from 1 to 0 . This matrix shows the direct relationship between two barriers (Table 7).

\section{B. Fuzzy Direct Relationship Matrix (FDRM)}

Traditional MICMAC analysis considers binary types of relationship, but to find out the strength of the relationshipan

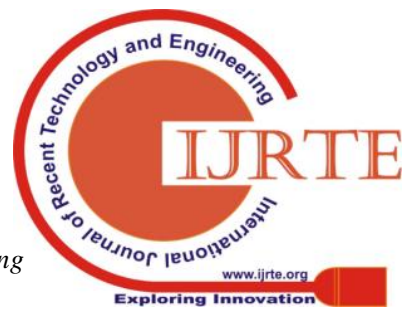


additional rating scale is introduced,which indicates the possibility of reachability (PoR). As ISM is based on experts' suggestions, in this case too, the expert's opinion was taken (Table 8).

To find out FDRM, values suggested by experts are taken into consideration. The scale which is introduced for FDRM is converted to the useful matrix (Table 9).

Table 7: Binary Direct Relationship Matrix (BDRM)

\begin{tabular}{|l|l|l|l|l|l|l|l|l|l|}
\hline & B1 & B2 & B3 & B4 & B5 & B6 & B7 & B8 & B9 \\
\hline B1 & 0 & 0 & 1 & 1 & 1 & 1 & 1 & 1 & 1 \\
\hline B2 & 1 & 0 & 1 & 1 & 1 & 1 & 1 & 1 & 1 \\
\hline B3 & 1 & 1 & 0 & 1 & 1 & 1 & 1 & 1 & 0 \\
\hline B4 & 0 & 0 & 0 & 0 & 1 & 0 & 1 & 1 & 0 \\
\hline B5 & 0 & 0 & 0 & 1 & 0 & 1 & 1 & 1 & 0 \\
\hline B6 & 0 & 0 & 0 & 0 & 0 & 0 & 1 & 0 & 0 \\
\hline B7 & 0 & 0 & 1 & 1 & 1 & 1 & 0 & 1 & 0 \\
\hline B8 & 0 & 0 & 0 & 1 & 1 & 1 & 1 & 0 & 1 \\
\hline B9 & 0 & 0 & 1 & 1 & 1 & 1 & 1 & 1 & 0 \\
\hline
\end{tabular}

Table 8: Scale for Fuzzy Direct Reachability Matrix (FDRM)

\begin{tabular}{|c|c|c|c|c|c|c|}
\hline$\stackrel{2}{2}$ 乙 & $\mathrm{N}$ & $\mathrm{L}$ & $\mathrm{M}$ & $\mathrm{H}$ & $\mathrm{VH}$ & $\mathrm{C}$ \\
\hline $\begin{array}{c}\text { Value } \\
0\end{array}$ & 0.1 & 0.3 & 0.5 & 0.7 & 0.9 & 1.0 \\
\hline
\end{tabular}

Table 9: Fuzzy Direct Reachability Matrix

\begin{tabular}{|l|l|l|l|l|l|l|l|l|l|}
\hline & B1 & B2 & B3 & B4 & B5 & B6 & B7 & B8 & B9 \\
\hline B1 & 0.9 & 0.5 & 0.7 & 0.9 & 0.7 & 0.7 & 0.7 & 0.7 & 0.3 \\
\hline B2 & 0.3 & 0.9 & 0.5 & 0.0 & 0.1 & 0 & 0.0 & 0.7 & 0.7 \\
\hline B3 & 0.7 & 0.5 & 0.9 & 0.1 & 0.3 & 0.3 & 0.0 & 0.5 & 0.5 \\
\hline B4 & 0.7 & 0.0 & 0.1 & 0.9 & 0.5 & 0.5 & 0.3 & 0.5 & 0.0 \\
\hline B5 & 0.5 & 0.0 & 0.0 & 0.7 & 0.9 & 0.7 & 0.5 & 0.5 & 0.0 \\
\hline B6 & 0.5 & 0.3 & 0.5 & 0.7 & 0.0 & 0.9 & 0.7 & 0.7 & 0.9 \\
\hline B7 & 0.5 & 0.5 & 0.1 & 0.7 & 0.3 & 0.7 & 0.9 & 0.3 & 0.0 \\
\hline B8 & 0.1 & 0.5 & 0.7 & 0.5 & 0.3 & 0.7 & 0.3 & 0.9 & 0.9 \\
\hline B9 & 0.3 & 0.7 & 0.5 & 0.1 & 0.0 & 0.5 & 0.0 & 0.7 & 0.9 \\
\hline
\end{tabular}

\section{F. Fuzzy MICMAC Stabilized Matrix}

This matrix is obtained by multiplication of fuzzy set A (initial matrix) and fuzzy set B (FDRM). Multiplication proceed with the given law: $\mathrm{C}=\mathrm{A} \times \mathrm{B}=[\max \{\min (\mathrm{aij}, \mathrm{bij})\}]$, where $A=\{$ aij $\}$ and $B=\{$ bij $\}$.

The fuzzy MICMAC stabilized matrix is developed (Table 10). The driving power of barriers is derived by summing up all entries in the row where dependence power is derived by summing up all entries in the column. With the support of driving and dependence power of all barriers, a graph is drawn,which is called driving and dependence power diagram (Malviya et al., 2015).

Table 10: Fuzzy MICMAC stabilized matrix

\begin{tabular}{|c|c|c|c|c|c|c|c|c|c|c|}
\hline & B1 & B2 & B3 & B4 & B5 & B6 & B7 & B8 & B9 & Erow \\
\hline B1 & 0.9 & 0.5 & 0.7 & & 7 & 0.7 & 7 & 7 & 0.3 & 6.1 \\
\hline B2 & 0.5 & 0.9 & 0.5 & 0.5 & 0.3 & 0.5 & 0.3 & 0.7 & 0.7 & 9 \\
\hline B3 & 0.7 & 0.5 & 0.9 & 0.5 & 0.3 & 0.5 & 0.3 & 0.5 & 0.5 & 4.7 \\
\hline B4 & 0.7 & 0.1 & 0.1 & 0.9 & 0.5 & 0.5 & 0.3 & 0.5 & 0.1 & 3.7 \\
\hline B5 & 0.5 & 0.1 & 0.1 & 0.7 & 0.9 & 0.7 & 0.5 & 0.5 & 0.3 & 4.3 \\
\hline B6 & 0.5 & 0.3 & 0.5 & 0.7 & 0.0 & 0.9 & 0.7 & 0.7 & 0.9 & 5.2 \\
\hline B7 & 0.5 & 0.5 & 0.3 & 0.7 & 0.3 & 0.7 & 0.9 & 0.3 & 0.3 & 4.5 \\
\hline B8 & 0.3 & 0.5 & 0.7 & 0.5 & 0 . & 0.7 & 0 . & 0.9 & 0.9 & 5.1 \\
\hline B9 & 0.3 & 0.7 & 0.5 & 0.5 & 0.3 & 0.5 & 0.3 & 0.7 & 0.9 & 4.7 \\
\hline$\sum$ col & 4.9 & 4.1 & 4.3 & 5.9 & 3.6 & 5.7 & 4.3 & 5.5 & 4.9 & 43.2 \\
\hline
\end{tabular}

\section{G. Driving and Dependence Power Diagram (DDPD)}

The diagram that is drawn with the support of the driving and dependence power of all barriers that formulates from the fuzzy MICMAC stabilized matrix (Table 10). In this diagram, barriers are divided into four clusters according to their driving and dependence power.

The four clusters are represented figure and narrated as, A. Linkage GSCM barriers (cluster 1)

Barriers having high driving power along with dependence power are categorized into this cluster. If there is any change in the barriers of this cluster, this has a significant effect on other barriers. These are unsteady barriers in nature,and due to this reason sometimes their effect on others is more and sometimes less. There are four barriers which are found in this cluster,and those are top management support (B1), benchmarking (B6), green design and education (B8), CO2 emission norms (B9).

\section{B. Independent GSCM barriers (cluster 2)}

Those barriers are having strong driving power, but weak dependence power is categorized into this cluster. These barriers should be taken care of a priority basis as they are independent barriers,andthey influence other barriers,speciallydependant barriers. The DDPD, government support (B2), financial constraints (B3), and performance measurement system (B7) are independent barriers (see Fig. 3).

\section{Autonomous GSCM barriers (cluster 3)}

Barriers having weak driving power along with dependence power are categorized into this cluster. These barriers are disconnected links of the system as they do not influence much on the system. In fig.3 environmental, ethical standard (B5) is the only autonomous barrier that has very few links with other barriers.

\section{Dependent GSCM barriers (cluster 4)}

These barriers with durable dependence power but not reliable driving power. These are called dependent barriers as they have delicate driving power,andhence, they do not influence other barriers. They depend on independent and linkage barriers. Management should concentrate highly on these barriers while implementing GSCM. The organizational culture (B4) is the only dependent barrier among all nine barriers (see Fig.3).

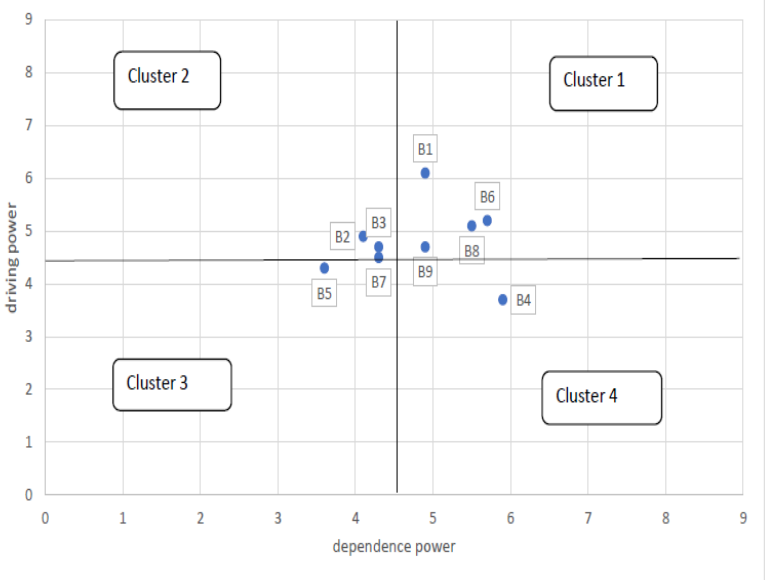

Fig 3: Driving and Dependence Power Diagram

Published By:

Blue Eyes Intelligence Engineering 


\section{CONCLUSION}

The environmental consciousness among the industries are increasing day by day, and GSCM (GSCM) has come forth as an active mode to respond to institutional as well as environmental pressures. To gain a competitive advantage in the current market scenario, some companies are proactively approaching green practices. However, despite their hard work, Companies are facing problems while practicing GSCM due to some influential barriers. This study helps managers to understand how these barriers affect while practicing GSCM. This study comes through to understand and find the dominant barriers influencing GSCM. With the guidance of literature review and discussion sessions with four experts from academic as well as industrial in the field of SC management, nine barriers are identified influencing GSCM in Indian industry and studied thoroughly to find the relationship among them. In this study, an ISM based model is evolved to find out the interdependencies among the barriers and MICMAC analysis is done to find the driving and dependence power of each barrier assist in understanding which an independent barrier is, and which is dependent barrier and how they are linked to each other while influencing one another [26]. This study broadly supports the related literature review regarding ISM based model. Implementation of GSCM is acute, which requires a contribution from all levels of personnel, from low-level employees to top management (Govindan et al., 2014).

Identification of barriers to GSCM is challenging, and this study has developed a framework to eliminate the barriers identification difficulties to make green practice easy for managers. During the practice of GSCM, it is unattainable to eliminate all the barriers initially, and hence, industries must make out which are the most dominant barriers among all the nine barriers. Hence this study aids the managers in identifying the dominant barriers. The driving and dependence power diagram (DDPD) clearly show that top management support, government support, and benchmarking are the most dominant driving barrier among all nine barriers. Hence these barriers are the significant obstacles during GSCM adoption. Among these three dominant barriers, top management support and benchmarking have reliable dependence power, and hence, these are called as linkage barriers. That means their effect is more in a system,whereas government support has weak dependence power, and hence,it an independent barrier. That means no other barriers have a significant effect on government support, but it has a significant effect on the system. Hence managers should concentrate on their relationship with the government as a good relationship with the government such that both achieve a successful green practice. Organizational culture has low driving power as well as dependence power, and hence, it is called dependent barriers. That means organizational culture depends on other barriers, which conclude that if top management support and government support is excellent, then it makes an excellent organizational culture,which means there is a good workforce culture with active employee engagement. However, with the lack of top management support, there will not be a significant organizational culture impacts the organizational goals.
Financial constraints have reliable driving power, which means the cost of implementation of GSCM is one of the major obstacles. Hence most of the companies are failing to adopt green practices due to weak financial support. Small and medium-sized companies in India are not willing to adopt green practice as they do not have enough financial support. Green design and education have stable driving and dependence power, and hence, it is a linkage barrier.

That means it can have a significant effect on the system. Green practices are still in the initial phase in India due to a lack of green education. Due to insufficient green design, it is tough for small and medium-sized enterprises to implement green practices to manufacture green product.

A diagraph is formed using the Interpretative Structural Modelling technique (ISM). The nine barriers are iterated at five levels. Benchmarking and performance measurement system are at the top level among all the nine barriers. That means these barriers are affected by lower-level barriers, and also, there has less encounter as compared to the remaining barriers. It reveals that these barriers are can be easily eradicate compared to other barriers. Organizational culture, environmental, ethical standard, and green design and education have occupied the same level, i.e., level two, and hence, it shows that these barriers have an equal impact on GSCM adoption. Financial constraints have occupied level three, whereas $\mathrm{CO}_{2}$ emission norms have occupied level four. Top management support and government support have occupied the last level, i.e., level five and it shows that these two are the most dominant barriers to green practice which also conclude that managers should concentrate on these two barriers while practicing GSCM.

\section{A. Managerial Implication:}

From the managerial point of view, the level partition of nine barriers in the ISM model contributes the managers to understand the barriers for tacking the real-world problem. The MICMAC analysis helps to find out the characteristics of barriers relating the healthy independence and driving power by eliminating the weak links. The managers' attempts to make an effective and efficient strategy from a competitive advantage and a higher return on investment point of view. The dependence power helps the managers to understand high priority barriers that make a practical impact on GSCM practice.

Thus, managers focus on high priority barriers in order to eliminate or minimize their effect to implement successful GSCM. However, this study helps the managers to focus on customers' demand, improve service, and product delivery also improves the company's performance efficiently.

\section{B.Limitation:}

There are some limitations to this study despite several contributions. Firstly, the ISM method of analysis is based on literature review-based barriers identified. The comprehensive literature review has tapered factors of barriers and reinforcing with the expert's opinion. This study could identify critical barriers. With the expert's domain working in the supply chain and green-related knowledge field, yet conventional approaches, as such surveys with large random sample sizes improves the generalizability of findings. The experts chosen are from academics and industries operating in e-commerce, manufacturing, 
and other respective domain. Hence driving and dependence power of the studied barriers might be different as different sectors have different dynamics, and hence, experts have different understand of the point of view. The perception of green supply chain changes with the quantitative survey method of finding barriers and analysis their drift on practicing GSCM. The driving and dependence power of all barriers identified using MICMAC analysis, which is based on the fuzzy binary method and hence, the exact values of driving and dependence power, may be compromised.

\section{Scope for further research work:}

This study has identified nine barriers specific to the small sample of SME's study related to this may be undertaken in identifying the other socio-economical barriers to get a clear picture of society demands. The $\mathrm{CO} 2$ emission is identified as significant barriers to GSCM, and future work may include other greenhouse gas to understand their effect on green practice. This study was done with qualitative methodology, i.e., using the ISM technique, and future work may include the quantitative way of analysis to understand the barriers and their interdependencies. Also, the MICMAC analysis may be replaced with a better quantitative method to make out the driving and dependence power of barriers, which helps to utilize resources more significantly and efficiently. As more and more practice of GSCM gets highlighted, more practitioners are required with the precise knowledge about the GSCM concept. Hence, identification of barriers and promoters for analyzing their interdependencies throw lights on developing a theoretical model that helps policymakers.

\section{REFERENCES}

1. Gunasekaran, A., Subramanian, N., \& Rahman, S. (2015). Green supply chain collaboration and incentives: Current trends and future directions.

2. Rastgara \& Naderi (2016), Evaluating pressures for green supply chain management adoption by grey theory approach, Decision Science Letters, 5,
https://dx.doi.org/10.5267/j.dsl.2016.1.003.

3. Mathiyazhagan, K., Diabat, A., Al-Refaie, A., \& Xu, L. (2015) Application of the analytical hierarchy process to evaluate pressures to implement green supply chain management. Journal of Cleaner Production, 107, 229-236.

4. Srivastava, S. K. (2007). Green supply-chain management: a state-of-the-art literature review. International journal of management reviews, 9(1), 53-80.

5. Parmar, V., \& Shah, H. G. (2016). A literature review on supply chain management barriers in manufacturing organization. International Journal of Engineering Development and Research, 4(1), 26-42.

6. Deepak, M., Nooral Haq, A., Mathiyazhagan, K. (2014) Identification of pressures, barriers and drivers for the implementation of green supply-chain management. All India Manufacturing Technology, Design and Research, 209, 1-6.

7. Parmar, M. N. K. (2016), Analysis of Barriers for Implementing GSCM in Small and Medium Sized Enterprises (SMEs) of India. International Journal of Humanities and Management Sciences (IJHMS),4(3), 219-223. ISSN 2320-4044 (Online) http://www.isaet.org/images/extraimages/ED416023.pdf

8. Chaghooshi, A. J. \& Zereshki, N. (2014). Barrier Analysis in GSCM Implementation in Auto Component Manufacturing in Iran. Global Journal of Management Studies and Researches, 1(1), 21-36.

9. Luthra, S., Kumar, V., Kumar, S., \& Haleem, A. (2011). Barriers to implement green supply chain management in automobile industry using interpretive structural modeling technique: An Indian perspective. Journal of Industrial Engineering and Management, 4(2), 231-257.

10. H. Abbasi (2016). Green supply chain management in India: An overview. International Journal of Advanced Research, 4(5). 385-390. https://dx.doi.org/10.21474/IJAR01/594.

11. Jayant, A., \& Azhar, M. (2014). Analysis of the barriers for implementing green supply chain management (GSCM) practices: an interpretive structural modeling (ISM) Approach. Procedia Engineering, 97, 2157-2166.

12. [Srivastav, P., \& Gaur, M. K. (2015). Barriers to Implement Green Supply Chain Management in Small Scale Industry using Interpretive Structural Modeling Technique-A North Indian Perspective. European Journal of Advances in Engineering and Technology, 2(2), 6-13.

13. Diabat, A., \& Govindan, K. (2011). An analysis of the drivers affecting the implementation of green supply chain management Resources, Conservation and Recycling, 55(6), 659-667.

14. de Sousa Jabbour, A. B. L., Júnior, S. A. V., Jabbour, C. J. C., Leal Filho, W., Souza, L. C., \& Castro, R. (2017). Toward greener supply chains: is there a role for the new ISO 50001 approach to energy and carbon management? Energy Efficiency. http://dx.doi.org/10.1007/s12053-016-9478-z.

15. Jayaram, J., \& Avittathur, B. (2015). Green supply chains: a perspective from an emerging economy. International Journal of Production Economics, 164, 234-244.

16. [Govindan, K., Diabat, A., \& Shankar, K. M. (2015). Analyzing the drivers of green manufacturing with fuzzy approach. Journal of Cleaner Production, 96, 182-19.

17. Gandhi, S., Mangla, S. K., Kumar, P., \& Kumar, D. (2015). Evaluating factors in implementation of successful green supply chain management using DEMATEL: a case study International Strategic Management Review, 3(1-2), 96-109.

18. M. A. Agi and R. Nishant. Understanding influential factors on implementing green supply chain management practices: An interpretive structural modelling analysis. Journal of Environment Management, March 2017; vol. 188, 351-363. https://dx.doi.org/10.1016/j.jenvman.2016.11.081.

19. Dashore, K. \& Sohani, N. (2013). Green supply chain management: A hierarchical framework for barriers. Journal of Sustainable Development, 4 (5), 2172-2182. http://www.ijettjournal.org published by seventh sense research group.

20. Balon, V., Sharma, A. K., \& Barua, M. K. (2016). Assessment of barriers in green supply chain management using ISM: A case study of the automobile industry in India. Global Business Review, 17(1), 116-135. https://dx.doi.org/10.1177/0972150915610701

21. Govindan, K., Kaliyan, M., Kannan, D., \& Haq, A. N. (2014). Barriers analysis for green supply chain management implementation in Indian industries using analytic hierarchy process. International Journal of Production Economics, 147, 555-568.

22. Malviya, R. K. \& Kant, R. (2017). Modeling the enablers of green supply chain management: An integrated ISM-fuzzy MICMAC approach." Benchmarking: An International Journal,24(2), 536-568.

23. Shibin, K. T., Gunasekaran, A., Papadopoulos, T., Dubey, R., Singh, M., \& Wamba, S. F. (2016). Enablers and barriers of flexible green supply chain management: A total interpretive structural modeling approach. Global Journal of Flexible Systems Management, 17(2), 171-188.https://dx.doi.org/10.1007/s40171-015-0109-X

24. Mudgal, R. K., Shankar, R., Talib, P., \& Raj, T. (2010). Modelling the barriers of green supply chain practices: an Indian perspective. International Journal of Logistics Systems and Management, 7(1), 81-107. https://dx.doi.org/10.1504/IJLSM.2010.033891.

25. Dube, A. S. \& Gawande. R. R. (2016) ISM-fuzzy MICMAC approach for analysis of GSCM enablers. International Journal of Logistics Systems and Management, 24(4), 426-451.

26. Ahluwalia, S., Singh, P., \& Sharma, J. (2018). Modelling and analysis of critical factors for phorbol ester degradation in Jatropha seed cake using ISM and MICMAC. International Journal of Environment and Waste Management, 21(4), 287-305.https://dx.doi.org/10.1504/IJEWM.2018.093437.

27. Balasubramanian, S. (2012). A hierarchical framework of barriers to green supply chain management in the construction sector. Journal of Sustainable Development, 5(10), 15-27. https://dx.doi.org/10.5539/jsd.v5n10p15.

\section{AUTHORS PROFILE}

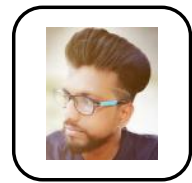

Mustafa Md. Sajidis passionate about supply chain and environmental consciousness. Has completed his B.Tech from Osmina University and currently preparing for UPSc exam. Contact: mustafamdsajid1@gmail.com and ORCID:0000-0003-2701-5926. 


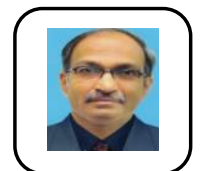

Shiva Prasad $\mathbf{H}$ Che has more than 28 years of teaching experiences. He was a member of the Board of National and International programs, conferences and has published twenty articles in International Journals. ORCID:0000-0002-1296-8970; Scopus: 54384313700.

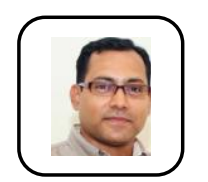

Yogesh PaiP has about 18 years of teaching and research experience.He has published papers in national and international forum. His ORCID id is https://orcid.org/0000-0002-9711-9336.

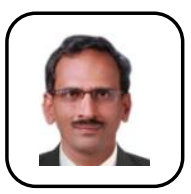

Alapati Vittaleswaris aMech. Engr and was in administrative positions as Asst. Placement Officer, Associate Director (Practice School \& Public Relations), Asso. Dir. (IIP), Deputy Director-Planning, MAHE and Director ICAS, he can be reached at +919845609961. 